\title{
Changes in Poverty and Income Inequality in Pakistan during the 1970s
}

\author{
HANS DE KRUIJK and MYRNA VAN LEEUWEN*
}

\section{INTRODUCTION}

According to Paul Streeten [10], the relationship between poverty eradication and reducing income inequalities is still an unsettled question. He mentions empirical studies of eleven countries. In ten of these countries, poverty and inequality move in the same direction, both increasing (Brazil, Mexico, Indonesia) or both declining (Korea, Taiwan, Sri Lanka, Costa Rica, Yugoslavia, China and Israel). The only exception is perhaps Kuwait, where poverty (of Kuwaiti citizens, but not of the large group of immigrant workers) has been reduced, while inequality has increased (explanation: oil wealth).

Gary Fields [1] examines six countries. Two of these - India and, in contradistinction to above, Brazil - show the 'exception' Streeten mentions. In India, poverty increases while inequality declines and in Brazil the situation is reverse.

The purpose of this paper is:

1. To examine the development of poverty and inequality in Pakistan during the 1970s. Already in this stage we can let the cat out of the bag by intimating that Pakistan belongs to the 'minority', viz. inequality increased while poverty decreased in Pakistan during the 1970s.

2. To decompose inequality into various components in order to identify the location, the magnitude and the change of various inequalities.

It is not easy to understand the working of the underlying process of the phenomenon of increasing inequality and simultaneous declining poverty in Pakistan. This paper does not pretend to explain this process. The stage of explanation is not reached before knowing which inequalities have increased (or declined) and what the

*The authors are associated with the Department of Economics, Erasmus University, Rotterdam. 
relative importance of various components in overall inequality increase has been. The contribution of this paper lies in supplying this information.

The plan of the paper is as follows. Section 2 measures changes in poverty during the decade by making use of four different indicators. Section 3 measures changes in income inequality (again four indicators). Section 4 decomposes the changes in income inequality. Finally, in Section 5 some conclusions are drawn.

\section{CHANGES IN POVERTY}

Poverty line is an important concept for measuring poverty. All poverty indicators make use of this concept. Poverty line is defined as the line dividing the poor and the non-poor. In this paper we draw the line at the so-called basicneeds income level, which is the income level required to satisfy the basic needs of a household. (We consider the household as the accounting unit.) A household is considered to be poor if its income is less than the basic-needs income; and a household is not poor if its income is higher than or equal to the basic-needs income. Of course, determining the level of the basic-needs income is always arbitrary. Nevertheless, we need to fix it to calculate the indicators. It seems not unreasonable to fix the basic-needs income of a household in Pakistan in 1979 at Rs. 700/- per month (current prices). ${ }^{1}$ With the price index of 300 for $1979(1969-70=100)^{2}$ [6] , the basic-needs income for 1969-70 works out at Rs. 700/3 = Rs. 233/-. Even if the basic-needs income is fixed at any other level, this would not have a dramatic impact on the results because we are not interested in the level of poverty, but rather in the change in poverty between the two years.

Four different indicators ${ }^{3}$ are used to measure the extent of poverty in Pakistan in 1969-70 and 1979. These are as follows:

1. The share of households below the basic-needs income level: $F(X)$-index. This index is very rough. Firstly, it does not take into account the distance of average household income of the poor to the poverty line - the so-called 'poverty gap'. In other words, the index is not sensitive to a decrease in the average income of the poor. Secondly, the index is not sensitive to income transfers from the poor to the non-poor, nor to transfers between the poor themselves. A proper index measuring poverty has to take these points into account. See, for example, [9] .

2. The level of average income of the poor plays a role in the $P$-index [3] . This index can be interpreted as: the percentage of total income that has to be transferred from the rich to the poor in order to bring the average

${ }^{1}$ This figure is based on own observations, and on discussions with many Pakistanis. The level is relatively low compared to other studies, e.g. IFAD (1984) chooses Rs. $800 /$ - as a proxy for the poverty line in rural areas in 1979.

Pakistan Economic Survey, 1982-83 [6] income of poor households to the basic-needs income level. This index has a substantial disadvantage. $P$ decreases if the average income of the non-poor increases while the average income of the poor does not change. In other words, poverty decreases if the rich become richer while the poor remain poor. This is an unacceptable feature of a poverty index.

3. The $P^{\prime}$-index does not relate the 'poverty gap' to the average household income of the entire population including the rich. Instead, it relates the 'poverty gap' to the basic-needs income. This index, measuring the so-called 'poverty intensity' or the 'poverty gap ratio', is independent of the income of the non-poor. For this reason $P^{\prime}$ is preferable to $P$.

4. The index developed by Sen [9], which we shall call the Psen(t)-index, suppresses the disadvantages mentioned above and also takes into account the inequality between the poor. The latter implies that poverty increases if the average income of the poor remains the same while inequality between the poor increases.

Table 1 presents the extent of changes in poverty for Pakistan as a whole as well as for its urban and rural areas separately. ${ }^{4}$

All indicators show a huge decrease of poverty in Pakistan during the 1970s. Poverty intensity has decreased by about 50 percent $\left(P^{\prime}\right)$. By combining the results of various indicators one notes that this decrease of poverty intensity appears to be due partly to a decreasing percentage of the households below the poverty line (about 34 percent, $F$-index) and partly to an increase in the average income of the remaining poor (about 15 percent, the difference between the change of $P^{\prime}$ and that of $F$ ). As far as the difference between urban and rural areas is concerned, Table 1 shows that the stronger appearance of poverty in rural areas in 1969-70 was not removed in 1979. On the contrary, poverty reduction was slightly lower in rural areas than in urban areas. Further, by combining the relative changes of $P$ and $P^{\prime}$ one can conclude that the increase in the average income of the non-poor is greater than the increase in the income of the poor. Therefore, inequality has increased, not only between rural and urban areas but also between households within these areas. This will be discussed further in the next section.

\section{CHANGES IN INCOME INEQUALITY}

In this section, changes in income inequality in Pakistan as a whole and in rura and urban areas between 1969-70 and 1979 are measured according to the following four indicators: Theil coefficient, Gini coefficient, coefficient of variation, and the

\footnotetext{
${ }^{4}$ Some remarks about the data based are made in Appendix I.
} 
Table 1

Poverty Indicators, Pakistan and its Urban and Rural Areas: 1969-70 and 1979

\begin{tabular}{llll}
\hline Area/Indicators & $1969-70$ & 1979 & Relative Change \\
\hline Pakistan & & & \\
$F$-index & .65 & .43 & $-34 \%$ \\
$P$-index & .25 & .09 & $-64 \%$ \\
$P^{\prime}$-index & .24 & .12 & $-49 \%$ \\
$P$ sent -index & .26 & .13 & $-48 \%$ \\
& & & \\
Urban Areas & & & $-40 \%$ \\
$F$-index & .50 & .30 & $-67 \%$ \\
$P$-index & .12 & .04 & $-54 \%$ \\
$P^{\prime}$-index & .15 & .07 & $-52 \%$ \\
$P$ sent -index & .17 & .08 & \\
& & & $-30 \%$ \\
Rural Areas & & .51 & $-62 \%$ \\
$F$-index & .73 & .13 & $-48 \%$ \\
$P$-index & .34 & .15 & $-46 \%$ \\
$P^{\prime}$-index & .29 & .17 & \\
$P$ sent -index & .31 & & \\
\hline
\end{tabular}

Source: Own calculations based on the Household Income and Expenditure Surveys of 1969-70 and $1979[7 ; 8]$.

standard deviation of logs of income. Further, Theil coefficients are decomposed into various factors.

For definitions and properties of the indicators mentioned above we refer to Kakwani [3]. One important aspect to be mentioned here is the bias of each indicator. The relative sensitivity of the Theil Inequality Coefficient decreases monotonously with increasing income. In other words, the Theil coefficient is more sensitive to a change in the lower part of the income distribution than to an equal change in the upper part of the distribution. The sensitivity of inequality as measured by the Gini coefficient is higher for the middle income groups than for those at the extremes of the distribution. The coefficient of variation has no bias in this respect. The relative sensitivity of inequality as measured by the standard deviation of logs first decreases monotonously with increasing income up to a certain point in the upper tail of the distribution and then becomes even negative beyond this point.
Table 2 presents the results of the change of household income inequality according to the four indicators. It appears that inequality increased in both urban and rural areas in Pakistan during 1969-70 and 1979 and that, according to all indicators, inequality is higher in urban areas than in rural areas.

Combining the results of various indicators, the increase in inequality appears to be relatively high in the lower income groups in rural areas - being the lowest income groups in the country - and in the highest income groups in rural areas. For the increase in the Theil coefficient, which is more sensitive to the lower income groups, substantially exceeds the increase in the Gini coefficient, which is more sensitive to the middle income groups. Further, like the Theil coefficient, the standard deviation of logs also attaches greater importance to income transfers at the lower end of the distribution, but a strange property of it is that if income is transferred to very rich households beyond a certain high income level, the inequality coefficient decreases rather than increases. Finally, the increase in the coefficient of

Table 2

Indicators of Household Income Inequality, Pakistan and its Urban and Rural Areas 1969-79

\begin{tabular}{lccc}
\hline Area/Indicators & $1969-70$ & 1979 & Relative Change \\
\hline Pakistan & & & \\
Theil coefficient & .21983 & .29089 & $32 \%$ \\
Gini coefficient & .32984 & .37697 & $14 \%$ \\
Coefficient of variation & .86518 & .98526 & $14 \%$ \\
Standard deviation of logs & .25773 & .29200 & $13 \%$ \\
Urban Areas & & & \\
Theil coefficient & .27373 & .31424 & $15 \%$ \\
Gini coefficient & .36299 & .40066 & $10 \%$ \\
Coefficient of variation & .98275 & .98235 & - \\
Standard deviation of logs & .27659 & .31499 & $14 \%$ \\
Rural Areas & & & \\
Theil coefficient & .16181 & .21101 & $30 \%$ \\
Gini coefficient & .29574 & .32129 & $9 \%$ \\
Coefficient of variation & .66516 & .83545 & $26 \%$ \\
Standard deviation of logs & .23651 & .25043 & $6 \%$ \\
\hline
\end{tabular}

Source: Own calculations based on the Household Income and Expenditure Surveys of 1969-70 and $1979[7 ; 8]$. 
variation is also relatively high. Remember that this indicator is equally sensitive to transfers at all levels of income. Therefore, it seems that inequality increase is relatively high in the tails of the distribution in rural areas.

However, the figures of Table 2 do not permit us to draw far-reaching conclusions. More disaggregated information is required. In the next section an attempt is made to provide this information by decomposing inequality changes.

\section{DECOMPOSITION OF CHANGES IN INCOME INEQUALITY}

Kemal [4], in a review of studies on income distribution in Pakistan, argues that 'very little attempt has been made to explain the level and the changes in income inequalities and to decompose income inequalities into inequalities due to occupation, sectors, rural-urban, etc.' Well, off we go!

Theil's measure for overall inequality $(T)$ can be decomposed into two parts: the 'explained' part (or the 'between' component) and the 'unexplained' part (or the 'within' component). If $T$ is decomposed into inequalities within and between urban and rural areas, the overall inequality coefficient $(T)$ is the weighed sum of inequalities within urban areas $(T U)$ and within rural areas $(T R)$ plus inequality between urban and rural areas $(T B)$, the weights being the respective income shares of urban $(Y U)$ and rural areas $(Y R)$. (See also Appendix 3.)

Table 3A and B present the values of the variables in 1969-70 and in 1979, respectively. Let's concentrate on these tables. At the head of the tables the overall Theil coefficients are displayed, which were .21983 in 1969-70 and .29089 in 1979, respectively. These overall Theil coefficients are decomposed first into inequalities within and between urban and rural areas. It appears that the 'explained' part, i.e. the inequality between rural and urban areas, is about 10 percent in 1969-70 and in 1979. (TB/T is $.01955 / .21983$ in $1969-70$ and $.0281 / .29089$ in 1979.) In other words, about 10 percent of the total household income inequality in Pakistan is due to inequality between urban and rural areas. Further, the tables show the contributions of inequalities within the respective regions to total inequality. Forty-two percent of total inequality was due to inequality within urban areas in 1969-70; this percentage increased to 54 percent in 1979 .

Apart from decomposing $T$ into inequalities within and between groups of households it is also possible to decompose $T$ according to different sources of income. In this way the decomposition technique is capable of determining the extent to which household income inequality is due to inequalities in labour earnings and inequalities in property incomes. However, in this paper this distinction between labour earnings and property incomes is not made; for this see Kruijk, [5]. Also for simplicity's sake we assume here that total household income consists of labour earnings. (In reality - or, better, as reported in $[7 ; 8]$ - labour earnings contribute to about 85 percent of the average household income both in 1969.70 and in 1979 ,
Table 3

Decomposition of Theil's Inequality Measure into Various Factors, Pakistan: $1969 \cdot 70$

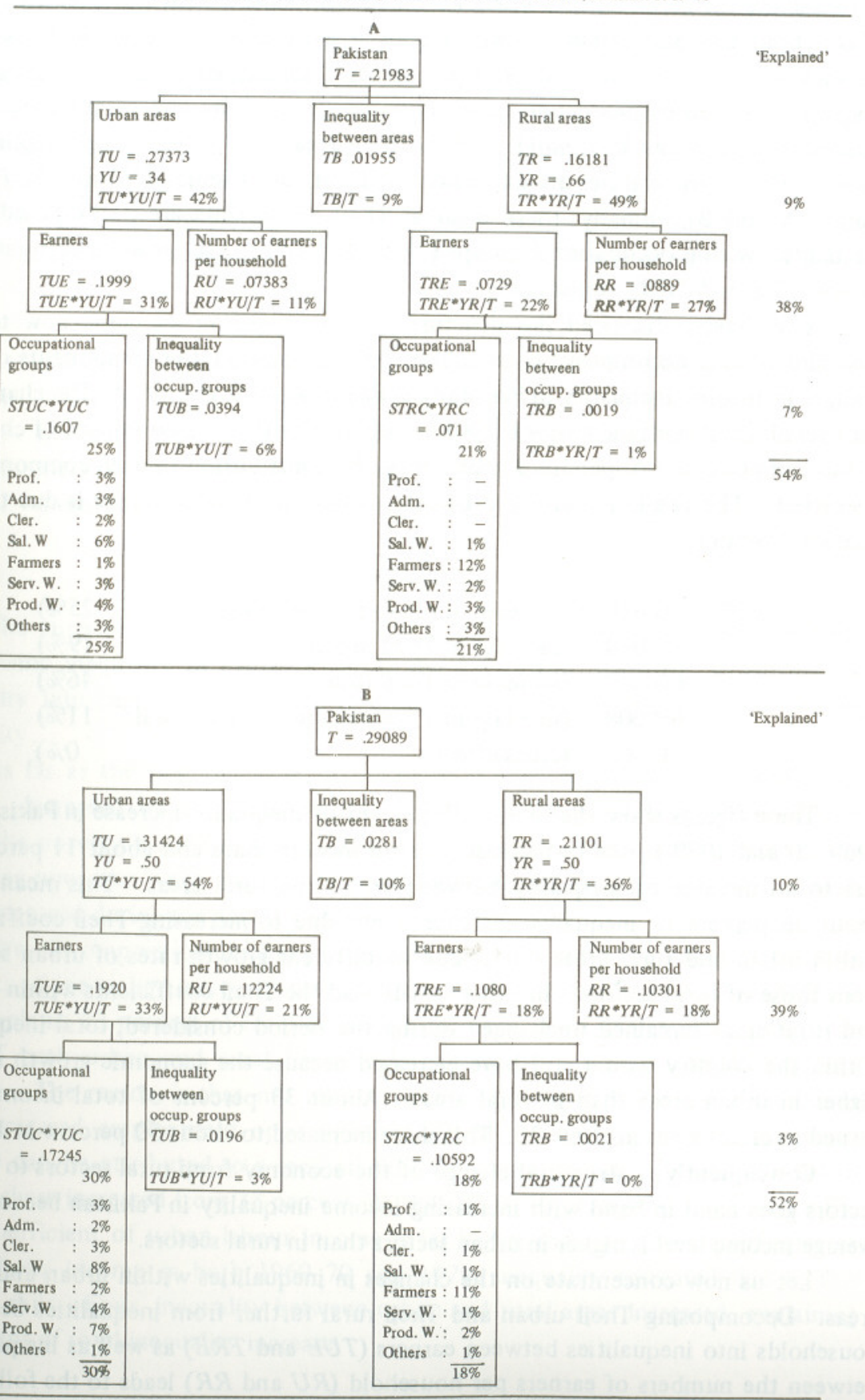


Another important factor explaining differences between household incomes is the number of earners per household. Clearly, it makes a great difference whether a household has one earner or two earners or even more. Therefore, household incomes are converted into incomes per earner. Subsequently, household income inequalities are decomposed into earners' income inequalities and inequalities in the number of earners per household both in urban areas and in rural areas. Again, the earners' income inequalities are expressed by Theil coefficients: TUE and TRE (see Table $3 \mathrm{~A}$ and B). Finally, these regional Theil coefficients are decomposed into inequalities within occupational groups (TUCs and TRCs) and between occupational groups (TUB and $T R B)$, respectively.

After having discussed the structure of decomposition we come now to the final aim of this decomposition excercise, viz. to pinpoint the components of the changes in income inequality in Pakistan between 1969-70 and 1979. The change in the overall Theil coefficient $d t=0.29089-0.21893=0.071$ is composed of changes of the components. Appendix 3 shows how the contribution of each component is calculated. The result is presented below. Overall inequality change is due to the following factors:

$0.071=0.018$ (increase in urban income share :

+0.014 (increase in Theil urban :

+0.033 (increase in Theil rural :

+0.008 (increase in $T$ between urban and rural:

-0.001 (cross effect :

These figures show that about 25 percent of inequality increase in Pakistan in 1969-70 and 1979 is due to increasing urban income share and about 11 percent is due to an increase of inequality between urban and rural areas. This means that about 36 percent of inequality increase is not due to increasing Theil coefficients within urban and rural areas but is due to different growth rates of urban sectors from those of rural sectors. In other words, had the Theil coefficients within urban and rural areas remained unchanged during the period considered, total inequality within the country would still have increased because the economic growth rate is higher in urban areas than in rural areas. About 33 percent of total income was earned in urban areas in 1969-70. This share increased to about 50 percent in 1979.

Consequently, a structural change of the economy from rural sectors to urban sectors goes hand in hand with increasing income inequality in Pakistan because the average income level is higher in urban sectors than in rural sectors.

Let us now concentrate on the changes in inequalities within urban and rural areas. Decomposing Thejl urban and Thejl rural further from inequalities between hou seholds into inequalities between earners (TUE and TRE) as well as inequalities etween the numbers of earners per household ( $R U$ and $R R$ ) leads to the following
Substituting the figures of Table $3 \mathrm{~A}$ and $\mathrm{B}$ into the formulas of Appendix 3 we find that the increase in inequality between urban households is completely due to the increasing participation rate of urban households and that inequality between urban workers did not change at all.

For rural areas the result is different. It appears that in rural areas, the increase in inequality between workers is more important (explaining 33 percent) than the effect of increasing participation rates per household (explaining 13 percent).

The results of this further decomposition show that the change in the overall Theil coefficient in Pakistan between 1969-70 and 1979 was due to the following factors:

1. increase in earners' income inequality in rural areas: $33 \%$

2. increasing urban income share:

3. increasing participation rate, urban households:

4. increasing participation rate, rural households:

5. increasing inequality between urban and rural areas:

\section{CONCLUSIONS}

The purpose of this paper was, firstly, to examine the development of poverty and income inequality in Pakistan during the 1970s and, secondly, to decompose inequality into various components in order to identify the location of increasing inequality

As far as the first objective of the paper is concerned, the figures show that poverty decreased by about 50 percent. Not only the percentage of households below the poverty line decreased by about 34 percent but the average income of the remaining poor also went up. At the same time, income inequality between households increased during the period concerned.

The decomposition technique applied in this paper has discovered four elements of inequality increase. One, increase in the inequality of earnings in rural areas explains 33 percent of total inequality increase. Two, increasing participation rates of both urban and rural households explain 32 percent of total inequality increase. The reason is that not all households have benefited to the same extent from increased employment opportunities. Three, 25 percent of total inequality increase can be attributed to a sectoral shift from rural to urban areas. The urban income share increased from 33 percent in $1969-70$ to 50 percent in 1979. Since the Theil coefficient of urban labour income is far higher than the Theil coefficient of rural labour income in both 1969-70 and 1979, inequality increased due to this sectoral shift. Four, inequality between urban and rural areas increased, explaining 11 percent of total inequality increase. 
Apparently Pakistan belong to a 'minority' of countries simultaneously facing both poverty reduction and inequality increase. As mentioned before, empirical studies by Streeten [10] and Fields [1] show that in most countries poverty and inequality move in the same direction, either increasing or declining. Usually, in the first instance higher income groups benefit from growth in these countries. It depends on their spending pattern whether a 'trickle down process' is realized. In most cases this has not happened.

As far as Pakistan is concerned, elements of the process described above are not unfamiliar. Since Pakistan is apparently an exceptional case, the forces working in the opposite direction must be stronger than in other countries. It is beyond the scope of this paper to fully explain the working of the underlying process that leads to increasing inequality and declining poverty in Pakistan. The contribu tion of this paper is that this question can be raised now. However, we shall mention one important factor in this context that is specific for Pakistan and in line with our findings, viz. emigration of large numbers of workers to Middle Eastern countries. The large remittances from these workers to their families have increased the income of a large section of the population. About 80 percent of these emigrants come from rural areas. The remittances of these workers reach families which used to be poor and which no longer belong to this category. These families spend this additional income not only on consumer goods but also on productive purposes like agricultura machinery, fertilizer, repair services, etc. These goods are produced in urban areas. Non-farm activities did not expand to a large extent in rural areas. The demand for labour increased - especially in urban sectors and to a smaller extent in agriculture while at the same time the domestic supply of labour decreased owing to emigration This process created shortages of certain categories of workers. Wages increased not only of skilled workers but also of unskilled workers. The rise in wages together with remit tances has reduced poverty, but has increased inequality at the same time because remittances and the rise in labour earnings are not spread evenly among households. Finally, as in most modernizing developing countries, incomes of professional workers, businessmen and other relatively high-income earners have increased as well

Appendix 1

\section{THE DATA BASE}

Of course, the reliability of the figures is as good as the data base permits. n fact, in Pakistan only the Household Income and Expenditure Survey (HIES) resents figures about the whole range of household incomes. Doubts about the eliability of HIES refer mainly to an understatement of incomes accruing to the nighest income group (see, e.g., Kemal, [4]) However, this understatement does not play a role as far as poverty is concerned (with the exception of the $P$-index). But inequality indicators, presented in the second part of this paper, most probably underestimate inequality. On the other hand, if both the HIES of 1969-70 and the HIES of 1979 suffer from the same defect, its impact on the change of inequality between the two years is lower.

Appendix 2

\section{MATHEMATICAL EXPRESSIONS OF THE FOUR POVERTY INDICATORS USED IN THIS PAPER}

(1) $\quad F(X)$-index: the percentage of households below the poverty line

(2) $\quad P$-index: $P=F(X) \frac{Y_{b}-Y_{p}}{Y}$

where

$Y_{b}=$ poverty line,

$Y_{P}=$ average household income of the poor, and

$Y=$ average income of all households, including the rich.

(3) $P^{\prime}$-index: $P^{\prime}=F(X) \frac{Y_{b}-Y_{p}}{Y_{b}}$

(4) $\operatorname{Psen}(t)$-index :

$$
P \text { sen }=F(X) \frac{Y_{b}-Y_{p}\left(1-G_{p}\right)}{Y_{b}}
$$

where $G p$ is the Gini index of household incomes below the poverty line. In this paper we used the Theil coefficient instead of the Gini coefficient as measure for inequality because it is easier to decompose the Theil coefficient. For this reason we redefine the Psen-index by substituting $G p$ by $T p$. We call this index the Psent index :

$$
\text { Psent }=F(X) \frac{Y_{b}-Y_{p}\left(1-T_{p}\right)}{Y_{b}}
$$

where $T_{p}$ is the Theil coefficient of incomes of the poor. 
where the third digit of each variable name ( 1 or 0 ) indicates the relevant year, year 1 (1979) and year $0(1969-70)$.

\section{COMPACT MATHEMATICAL EXPRESSIONS*}

The Theil coefficient $(T)$ can be defined as :

$$
T=\sum_{i} y_{i} \log \frac{y_{i}}{n_{i}}
$$

where

$$
\begin{aligned}
& y_{i}=\text { household income share of income class } i\left(\Sigma y_{i}=1\right), \text { and } \\
& n_{i}=\text { household share of income class } i\left(\Sigma n_{i}=1\right) .
\end{aligned}
$$

Decomposing $T$ into an urban component and a rural component, $T$ can be written s :

$$
T=T U^{*} Y U+T R^{*} Y R+T B
$$

where

$$
\begin{aligned}
& T U=\text { Theil coefficient within urban areas, } \\
& Y U=\text { urban income share, } \\
& T R=\text { Theil coefficient within rural areas, } \\
& Y R=\text { rural income share, and } \\
& T B=\text { Theil coefficient between urban and rural areas. }
\end{aligned}
$$

The change of the overall Theil coefficient between two years (year 1 being 1979 in our case and the base year 0 being 1969-70) can be written as :

$$
\begin{aligned}
d T= & T 1-T 0=T U 1^{*} Y U 1+T R 1^{*} Y R 1+T B 1-T U 0^{*} Y U 0 \\
& -T R 0^{*} Y R 0-T B 0
\end{aligned}
$$

fter rearranging we get:

$$
\begin{array}{rlrl}
T T= & (Y U 1-Y U 0) *(T U 0-T R 0) & & \text { increase in urban income share } \\
& +Y U 0(T U 1-T U 0) & & \text { increase in Theil urban } \\
& +Y R 0(T R 1-T R 0) & & \text { increase in Theil rural } \\
& +(T B 1-T B 0) & & \text { increase in } T \text { between urban/rural } \\
& +(Y U 1-Y U 0) *[(T U 1-T U 0)- & \text { cross effect })
\end{array}
$$

\section{(change due to:}

Decomposing $T U$ and $T R$ further into inequalities between earners (TUE and TRE) and inequalities between the numbers of earners per household ( $R U$ and $R R$ ), changes of 'within' components are disaggregated as follows:

$$
\begin{aligned}
& T U 1-T U 0=(T U E 1-T U E 0) \\
&+(\text { change of inequality between earners }) \\
& \text { (change of effect of different participation rates } \\
&\text { per household })
\end{aligned}
$$

Similarly for rural areas:

$T R 1-T R 0=(T R E 1-T R E 0)+(R R 1-R R 0)$

\section{REFERENCES}

1. Fields, Gary S. "Employment, Income Distribution and Economic Growth in Seven Small Open Economies”. Economic Journal. Vol. 94, No. 373. March 1984.

2. International Fund for Agricultural Development (IFAD). Agricultural Policy and Rural Poverty in Pakistan: Report of the Special Programming Mission to Pakistan. January 1984

3. Kakwani, Nanak C. Income Inequality and Poverty. New York: Oxford University Press (for World Bank). 1980.

4. Kemal, A. R. "Income Distribution in Pakistan: A Review". Islamabad: Pakistan Institute of Development Economics. April 1981. (Research Report Series No. 123)

5. Kruijk, Hans de. "Income Inequality Decomposition: The Case of Pakistan". Rotterdam: Erasmus University, Centre for Development Planning. 1985. (Discussion Paper Series; forthcoming)

6. Pakistan. Finance Division. Economic Adviser's Wing. Pakistan Economic Survey 1982-83. Islamabad. 1983.

7. Pakistan. Ministry of Finance, Planning and Development. Statistical Division. Hou sehol' Income \& Expenditure Survey: 1969-70. Karachi. 1973.

8. Pakistan. Statistics Division. Federal Bureau of Statistics. Household Income and Expenditure Survey: 1979. Karachi. 1983.

9. Sen, A. K. On Economic Inequality. London: Oxford University Press. 1973.

10. Streeten, Paul. "Basic Needs. Some Unsettled Questions". World Development. Vol. 12, No. 9. 1984. 


\section{Comments on \\ "Changes in Poverty and Income Inequality in Pakistan during the 1970s"}

The paper makes a very significant contribution to the analysis of income inequalities and poverty by explaining changes in inequalities by decomposing Theil's inequality coefficient. The changes in income inequality are explained in terms of those arising due to area, differences in the number of earners and various occupation groups. Three main objectives of the paper are:

(i) to examine trends in poverty and income inequalities in Pakistan;

(ii) to explain the phenomenon of rising inequalities and declining poverty; and

(iii) to identify the sources of increase in income inequalities.

In order to pursue these objectives, the author has used four poverty indices and four income inequality indices. The four poverty indices employed in the study are:

(i) $F(x)$ Index : Number of persons below the poverty line;

(ii) $P$-Index : Poverty gap, i.e. the average difference in actual income and the poverty line, as percentage of average income;

(iii) $P^{\prime}$-Index $\quad: \quad$ Poverty gap as a percentage of the income at which the poverty line is drawn; and

(iv) Psen : Poverty gap adjusted for inequality between the poor as a percentage of the income at which the poverty line is drawn.

It may be readily noted that all the four indices relate to the level at which the poverty line is drawn. The author has drawn the poverty line at a level of Rs 700 per month, assuming that this reflects the minimum needs. However, the authors claim that the choice of poverty line does not affect trends and come up with the conclusion that 34 percent of the households classified as poor in 1972 were no more poor in 1979.

That the level at which poverty line is drawn is immaterial in analysing trends in poverty is not well substantiated. The sensitivity analysis reveals that trends are very sensitive to the level of poverty line. For example, using essentially the same data, Cheema comes up with the conclusion that poverty may have somewhat increased. Therefore, more care needs to be taken in drawing poverty line.

Messrs Kruijk and Leeuwen have drawn the same poverty line for the rural and the urban areas. Since cost of living in rural areas is much below that in the urban areas, the same poverty line for both rural and urban areas is very misleading. It is interesting to note that when the poverty lines are drawn separately for rural and urban areas, the poverty declines in rural areas but increases in urban areas.

In order to analyse changes in income inequalities, the authors have employed Theil coefficient, Gini coefficient, coefficient of variation and standard deviations of logs. On the basis of all these four indices, income inequalities have shown an increase in both rural and urban areas.

The authors have tried to reconcile the rising inequalities and the declining poverty by resorting to remittances. It is argued that remittances are received by those who were the poorest and as such workers' remittances have led to a decline in poverty. At the same time, as the incomes of the recipients of remittances rose very high, they accentuated income inequalities. While this mechanism can explain the phenomenon, it is only a hypothesis which needs to be tested. The authors could have included this aspect in their decomposition excercise, of course, depending on the availability of the relevant data.

Rising inequalities and declining poverty can also be explained through many other mechanisms. One such explanation can be through changes in the wage rate. As Irfan and Ahmad have shown, the wages of the lowest paid workers have gone up while those of others have gone down. Higher wages of low paid employees leads to a reduction in poverty, and a general reduction in wage bill relative to non-wage income tends to accentuate income inequalities. This hypothesis can also be tested through decomposition for which the relevant data are readily available.

The most important analysis contained in the paper relates to decomposition of Theil's Index into the following factors:

(a) Urban - rural differential;

(b) Differential in number of earners in a household; and

(c) Differential in earnings of various occupational groups.

A very interesting result emerging from the analysis is that increasing urbanization is responsible for 11 percent of the increase in inequalities. However, much larger proportion, i.e. 25 percent, of the increase in inequalities is accounted for by the increase in urban and rural incomes; the increase in urban incomes is entirely due to the differential in the participation rates across the households.

In sum, the paper presents very illuminating analysis. However, there is a need to draw the poverty line more carefully and also separately for urban and rural areas. 
Moreover, the increase in income inequalities needs a more careful analysis, and the decomposition excercise has to be extended to various other aspects.

Joint Economic Adviser,

Dr A. R. Kemal Government of Pakistan, Islamabad 